\title{
Redefining Resilience: A Process-centered Approach for Interventions with Child Sexual Abuse Survivors
}

\author{
Tanya Elizabeth Michelle Defferary ${ }^{1, *}$, John Gregory Howcroft ${ }^{1}$, Louise Anne Stroud ${ }^{2}$ \\ ${ }^{1}$ Department of Psychology, Nelson Mandela University, Port Elizabeth, South Africa \\ ${ }^{2}$ School of Behavioural Sciences, Nelson Mandela University, Port Elizabeth, South Africa
}

Copyright $\mathrm{C} 2018$ by authors, all rights reserved. Authors agree that this article remains permanently open access under the terms of the Creative Commons Attribution License 4.0 International License

\begin{abstract}
Resilience is a term that is often used in a general and decontextualized way, both in psychology and related disciplines. This becomes a problem as it can impact the effectiveness of interventions. Researchers have long argued whether resilience should be defined as an outcome or process. This article conceptualizes resilience as a process-centered construct in relation to child sexual abuse (CSA). Findings were derived through the use of a convergent parallel mixed methods research study, from a South Africa sample, a country which has some of the highest rates of CSA globally. It explored the impact of resilience upon the psychosocial sequelae of CSA survivors. The findings indicate resilience should be viewed as a process rather than a fixed state, resulting in recommendations to approach the treatment of survivors of CSA. This opens the door for further research on this topic and for the improvement of intervention and treatment practices.
\end{abstract}

Keywords Child Sexual Abuse, Intervention, Mixed Methods Research, Resilience, Process-Centered Construct

\section{Introduction}

The reason some individuals respond to adverse circumstances in maladaptive ways, whereas others adapt positively, is something that has perplexed psychologists and researchers for years. This has led to the need for more empirically driven research, in the field of resilience, to explore and explain this phenomenon [1].

It is the authors' opinion that the definitions and terminology used in relation to the construct of resilience need to be redefined. This is because normative assumptions have arisen surrounding the meaning of the word, resulting in 'resilience' being used as a catch-all phrase. This can be problematic. A clearer understanding and re-conceptualization of the term is needed, as this can impact how treatment interventions are formulated, especially in this case, in relation to child sexual abuse (CSA) survivors.

This article is based on a larger, retrospective study of adult CSA survivors that looked at the impact of resilience and attachment, in relation to the psychosocial sequelae of child sexual abuse. The focus of this article however, centers on the possible impact that resilience has upon the psychosocial sequelae which might be experienced by a CSA survivor. The aim is to describe the way survivors utilize varying coping mechanisms within a process-centered resilience approach.

There exists a long-standing debate among resilience researcher as to whether resilience should be defined as an outcome or a process. For example, researchers such as Bonanno, Westphal and Mancini [2] and McCubbin [3] speak about an outcomes-focused approach to resilience, whereas Herrman et al., [4] and Rutter [5] emphasize a process-focused one.

These distinctions are essential, because the way the term is conceptualized, impacts on the attributed meanings and applications of the word in practice. As Luthar, Ciccetti and Becker [6] state, practitioners and resilience researchers should be clear on how findings are reported; which should not be forced under a single heading of 'resilience'? A lack of clarity will not only influence the criteria used to determine successful coping with an adverse experience, but additionally, how this experience is quantified [6]. Luthar et al., [6] point out that while the boundaries of a construct are being operationalized, as is the case with resilience, researchers should continuously consolidate newer findings within the field [6].

Based on existing literature, this article considers two different approaches to resilience, both as an outcome and a process. It then describes the methodology used in a South African study of resilience among CSA survivors. From this study it emerged that a process-approach may be more efficacious in interventions with, and the treatment of, CSA. Finally, a discussion of possible recommendations for future treatment practices in relation to these findings is 
discussed.

\section{Literature Review}

South Africa has some of the highest rates of child sexual abuse in the world [7]. The Optimus Study [8], a report on Sexual Victimization of children in South Africa, included statistics released by the South African Police Services in 2013/2014, which showed that 51 children are sexually abused in South Africa each day, and on average 18524 per year. This highlights the necessity for research to be conducted in this field [8].

The Center for Disease Control and Prevention [9], highlights the pervasive impact which negative childhood experiences (ACEs) can have on a child's functioning in adulthood. Such experiences can include childhood physical, emotional or sexual abuse [9]. Exposure to an ACE has been found to result in a number of health and social problems later in life. This could result in the individual not reaching his/her full potential, it can also lead to him/her engaging in risky or unhealthy behaviors, which have negative health consequences. Furthermore, ACEs can result in chronic health problems, and even premature death [9]

The focus of CSA research over the past 20 years has shifted from focusing on the negative short- and long-term effects of an adverse experience, to how survivors manage to overcome and cope with the trauma [10]. In essence these studies have moved from a pathogenic to a fortigenic focus. During this time, researchers have begun reporting on the resilience outcomes and post-traumatic growth, which survivors experience after such events [10].

Larkin, Beckos and Shields [11] highlight the importance of helping a child develop resilience in response to ACEs, specifically in the realm of social support. Similarly, Bethell, Newacheck, Hawes and Lafon (2014), report findings which suggest that helping a child, who has experienced an ACE, to develop resilience, can mitigate the negative impacts this experience may have, both in the short and long-term [11].

At this point there is not one overarching description in place to describe resilience [3]. It has been found that an individual might exhibit resilience in one context, but not within another. As a result, resilience does not translate across all life experiences [3]. It is therefore postulated that resilience should in fact be considered context-specific. Therefore, the best solution might be to conceptualize a number of different contextual definitions of resilience [12].

It is the author's view that one of the core distinctions which needs to be made when aiming to conceptualize the term resilience, more specifically in relation to CSA, is whether it should be viewed as a process or an outcome. When viewed as an outcome, the individual is seen as resilient, when she or he is able to overcome the adverse challenges which were experienced [2]. Resilience is then used to define the consequence of overcoming an experience. This is the end product of the process [2, 3], where the individual remains in a resilient state of being after the fact. As a process, resilience is dynamic in nature. As Rutter [5] describes:'Resilience involves a range of processes that bring together quite diverse mechanisms operating before, during and after the encounter with the stress experience or adversity that is being considered' [5].

The authors therefore suggest that in this way resilience is seen as an ever-changing process of coping with adverse challenges which the individual is faced with in the particular context. From this process-centered approach, resilience is also seen to act as a mediating factor, buffering the effect which the CSA might have on the individual. This article advocates the latter of the two approaches, namely that resilience is a process, and will use CSA as a specific arena of trauma management to argue for this position.

In line with this position, Bogar et al., [13] identified a number of processes that CSA survivors utilize when developing resilience. They grouped these into four main process clusters: coping strategies, refocusing and moving on, active healing, and achieving closure. These processes are primarily behavioral and cognitive in nature, and encompass the methods that survivors use to actively cope with the CSA [13]. Survivors utilized the process of refocusing and moving on, by finding other areas of focus, rather than the abuse. This was found to include educational interests, family, and other social relationships. In most cases the survivors made a conscious decision to refocus their minds into these alternate areas. Once individuals were focused on these adaptive areas of functioning, the process of moving on began [13].

Active healing is an active and motivated stance, where survivors entered into some form of therapy, or talked through the experience with others [13]. Daigneault et al., [14] found that survivors, who had taken part in a support group, reported higher levels of resilience. The ability to reach closure after the CSA, was an active process of meaning-making and forgiveness (self and others, including the perpetrator) [13]. The coping strategies which survivors used included: cognitive appraisal/reappraisal, making meaning of the event [15-20], reworking previously held beliefs [19], and disclosure [16].

Disclosure has also been found to be an instrumental part of the process of resilience [16]. Disclosure can be a difficult process as the survivor is often fearful of the outcomes, for example, whether they will be believed. However, disclosure which is met with belief and acceptance on the part of the confidant has been found to facilitate the resilience process [16].

It is important to note that resilience is not a single construct, but rather a concept comprising many facets [1, 21-23] and dimensions [23]. Wu et al., [23] identify various individual characteristics which are implicated in resilience. These include: active coping, cognitive 
reappraisal, social support, optimism, humor, trait mindfulness, physical exercise and prosocial behavior. These factors all impact on how the individual responds to the adversity, and how vulnerable she or he is to developing negative outcomes after the experience [24]. Walsh et al., [22] highlight that the styles and processes of coping that a CSA survivor employs, do not follow a linear process, but rather one that is complex and multifaceted. If the survivor uses positive coping styles, such as reaching out to support systems, or finding meaning from the experience, the outcomes are more likely to be positive and adaptive [22]. From this it can be seen that the development of resilience can be fostered through factors both intrinsic and extrinsic to the individual.

\subsection{Extrinsic Factors}

It is erroneous to think that an individual should develop resilience without support. Seeking help from others can actually shorten the time it takes for individuals to overcome their adversity [18]. In the case of CSA, receiving external support elicits the impact that the individual's environment has on him. Interpersonal factors such as family involvement and support [25, 26], educational engagement $[25,27]$, interpersonal trust, and competence in establishing and maintaining relationships, are all factors which play a role [25]. Interpersonal trust and social support are important, as they act as a buffer against the negative experiences of some of the social consequences which might impact that survivor. This could include the shame, stigmatization, and broken trust that might arise out of the experience [25]. It is important for the child to have a system which motivates and helps him or her to develop the skills needed, to grow and adapt to his or her environment [12].

\subsection{Intrinsic Factors}

Intrinsic resilience factors have been found to include aspects such as competence, high self-regard, spirituality [13] optimism [25, 26, 28], as well as being interpersonally skilled [13] and meaning-making [22]. These intrinsic processes are largely inherent within the individual, and are quite subjective in nature.

Therefore, when exploring the concept of resilience and its role regarding the outcomes a CSA survivor might experience, a number of factors need to be taken into consideration when conceptualizing the construct of resilience. The first is that resilience is a process; the next is that resilience is a subjective construct and, finally, that resilience is partly context-specific.

\section{Materials and Methods}

\subsection{Research Design}

A convergent parallel mixed methods research design was followed. This method was chosen in order to provide more robust inferences and answers that other methodologies are possibly not able to yield. This was conceived with the hope of "presenting a greater diversity of divergent views" [29, pp, 14-15]. It was retrospective in nature, as adult participants were required to provide information about child sexual abuse (CSA,) which occurred when they were under the age of 16 . This specific age was utilized due to the definitional criteria of CSA provided by Miller, Johnson and Johnson [30].

The research was realized in three phases. Phase 1 was quantitative in nature, and was implemented through a small scale, cross-sectional survey. Phase 2 related to the qualitative portion of the research. This followed a phenomenological research design. Phase 3 involved the integration and interpretation of the findings of the first two phases, and is discussed later in this article.

\subsubsection{Sampling, Data Collection and Data Analysis}

Phase 1

The sample consisted of 304 participants, and was comprised of South African, undergraduate, tertiary education students, who were identified through nonprobability convenience sampling. A number of researchers have argued the advantages and disadvantages of using university students as a sample for studies of CSA. One of the main arguments against using university students as a sample in such a study is that individuals who experience CSA, may never reach university level. However, a study conducted by Murthi, Servaty-Seib and Elliott [31] on the relationship between various dimensions of self-esteem and CSA, found that CSA survivors do not experience difficulties with academic self-esteem. Rind, Tromovitch and Bauserman [32] similarly state that university students are just as likely as members of the general public to have experienced a CSA. Roche et al., [33] stated that using a university sample strengthened their study, as it allowed them to access a large sample. Therefore, it can be concluded that survivors of CSA could be found in a university setting, and the researcher felt confident in using this sample.

Of this group, 290 participants supplied information about their gender; data analysis was conducted with this sample ( $26.67 \%$ male; $73.33 \%$ female). These participants' ages ranged from 18 - 50 years, and included races representative of South African demographics (black, $54.76 \%$; colored, $25 \%$, and white, $19.05 \%$ ). A total of 90 participants (29.61\%) reported being sexually abused when they were under the age of 16 , and were referred to as the 'incident group'. Of this group $32,43 \%$ were males and $30.56 \%$ were females. The 'no-incident group' consisted of 190 participants $(62.50 \%)$.

The data was collected through the use of a biographical questionnaire, the Early Sexual Experiences Checklist [34, 35] and the Resilience Scale [36]. Data were analyzed using descriptive and inferential statistical analyses. 
The biographical questionnaire was used to gather demographic information about the participants. Miller and Johnson [34] found a one-month test-retest reliability of .92 for the ESEC using Cohen's Kappa. In this study the amended version [35] of the Early Sexual Experiences Checklist (ESEC), was utilized to gather additional data regarding the way participants reported being affected by the CSA. This amended version comprised of two additional tables, each in the format of a 7 point Likert Scale. The items on the Likert scale included possible ways in which the participants were affected by the CSA. These included: anxiety, low self-esteem, sexual guilt, confusion about sexual orientation, behavior problems and self-destructive behaviors. The first table required participants to rate the extent, and the different ways, in which they were affected by their experience at the time of the event. The second table required participants to rate the extent, and the different ways in which they were currently still being affected by their experience.

The Resilience Scale (RS) developed by Wagnild and Young [36] was used to ascertain the current resilience levels of the participants. The RS is a 25 -item scale, which focuses on determining an individual's resilience score. It looks at identifying five core characteristics that are related to resilience [21]. Wagnild [21] describes these characteristics as: (1) meaningful life (purpose), (2) perseverance, (3) self-reliance, (4) equanimity, and (5) coming home to yourself (existential aloneness). The RS was used previously in a South African study conducted by Hutchinson, Stuart and Pretorius [37]. The study was conducted using a sample of 620 tertiary education students and members of the private sector in South Africa. In the study the researchers found that the resilience scale exhibits reliability and validity, when it was used on a South African sample. The study did not report any limitations with using this measure [37]. The reliability of the measure is shown by an Alpha coefficient of 0.91. High concurrent validity was also found [36].

\section{Phase 2}

Data was collected through 9 semi-structured interviews which were obtained through purposive sampling. Interviews were terminated at 9 participants, as data saturation had been achieved. These participants were volunteers from the original sample, who had experienced a CSA. Two were males and seven were females. Four of the participants were black, three were white, and two were colored. Data were analyzed using Tesch's Eight Step Coding Process as adapted from Creswell [38]. Lincoln and Guba's [39] model of trustworthiness was employed to ensure the quality and rigor of the results were maintained. Once the data was transcribed and coded, it was cross-checked by an independent coder who had experience in this form of data analysis, to ensure the reliability of the coding system used by the researcher [38].

\subsection{Ethics}

The study adhered to both international and national standards which govern research conducted using human participants [40]. The study ensured that the ethical guidelines of institutional and informed consent, confidentiality, and privacy, were complied with [40]. Furthermore, the ethical principles of dignity and respect [41], as well as Kitchener's (1984) five moral principles of autonomy, nonmaleficence, beneficence, justice and fidelity, were kept in mind at all times [41, 42]. All institutional ethical processes were followed, and the study received institutional ethics approval prior to commencement.

\subsection{Results}

\section{Phase 1}

An investigation into the resilience levels of participants did not yield any statistically significant results, however, this in itself held significance. In other words, after conducting a Chi-Squared Test and a One-Way ANOVA to explore whether experiencing CSA had an impact on resilience, it was found that all respondents' resilience scores, irrespective of whether they had a CSA or not, fell between the 'moderately low' and 'moderately high' resilience ranges. A more in-depth analysis was conducted to determine whether the severity of the CSA had an impact on resilience. Again, the results found that respondents, irrespective of severity, were more likely to report having moderate levels of resilience.

Therefore, even though it was thought that a CSA survivor's resilience score (incident group) would be different when compared to the 'no-incident group', this was not the case. Had the study been conducted using only quantitative analysis, the significance of these findings would not have emerged. However, when compared to the qualitative results obtained in phase 2, a more comprehensive picture of resilience in CSA survivors was uncovered, which supports a process-focused approach.

\section{Phase 2}

Resilience and coping were one of several themes that emerged during the thematic analysis of the transcribed interviews. Other themes included: manner of disclosure, reasons for delayed disclosure, relationship to the confidant, confidant's response to disclosure, effects of the response to disclosure, the impact of the CSA upon the survivor, impact of the CSA on relationships, advice to professionals, the confidant, and the survivor. The scope of this article will be restricted only to resilience. It is however acknowledged that there is a larger contextual and systemic coherence to the phenomenon of CSA, and that this should be taken into consideration in any treatment or intervention situation.

Pertaining to resilience and coping, further subthemes 
arose relating more specifically to intrinsic and extrinsic resilience processes employed by CSA survivors, both at the time of the CSA (this will be referred to as childhood resilience), and at the time that the research was conducted (this will be referred to as adulthood resilience).

Internal resilience processes were both positive and negative. The positive forms of internalized coping that the participants identified included praying, and taking charge, or taking control of their lives. Further positive coping mechanisms that were identified included the use of self-talk, self-affirmations, and self-forgiveness. For example, Participant Six said 'I just convinced myself that it wasn't my fault. Because I know, that if I blamed myself, then I would have lost it. So I think from a young age I just told myself ... this is going to stop one day, it's fine, it's going to be ok'. Unique themes that emerge was where a participant expressed her emotions through dance, reading, writing, and singing. Other unique themes that emerged related to one participant's use of optimism, and another, who said she gathered inspiration from other victims, and how they had coped with their experience.

The negative coping mechanisms that were used included denial and anger, as described by Participant Nine: 'My resilience, if you ask, was basically, forget, completely forget, get it out of my... my resilience to all this stress was anger'. However, these forms of coping were used in the initial month after the CSA, and participants thereafter reported using more positive forms of coping.

External methods of coping included eliciting support through social support networks comprising of parents, friends and partners. For example: 'I guess it was the support from mom. Ja, 'cause, um, like after everything had happened and then the whole family was around and things like that, she made sure that I felt safe around her and that I could basically, like, talk to her' (Participant Five).

Respondents reported that in adulthood the coping was facilitated by a change in their mind-set at some point during the recovery process. Participant Ten said 'It's tough, it's very tough, but if you told yourself, tell yourself... you must go forward, you see, no turning back'. Participant Three also discussed an internalized sense of coping through a gradual change in mind-set that helped coping with the experience: 'Ah, for myself. Ah, it helped me a lot, because I started to realize that okay, I, I can change, you see, so I don't have to stick in one point. Something happened in life, so it has to pass, you see, so I must look forward to, to continue with my life so I can do well' (Participant 3).

Some reported that the resilience they had developed since the CSA improved their ability to cope with life in general. Critical self-talk was another sub-theme that emerged: 'I told myself that it's not your fault I don't know what you could tell someone to convince them. I just told that to myself.'(Participant 5). A number of participants reported that they were still using external support, such as turning to a family member or a friend, for emotional support.

\section{Discussion}

The results of the study left a number of questions, relating to the CSA survivors' resilience, unanswered. The two major questions in relation to this study are:

- How should resilience be reconceptualised in relation to a trauma, such as child sexual abuse?

- Should resilience be conceptualized as a process, rather than an outcome, within the context of child sexual abuse?

The rest of this article will attempt to contextualize these questions and suggest that a process-approach may be most efficacious for dealing with CSA survivors. The themes that were identified in Phase 2 showed that participants from the incidence group tended to use similar, yet more evolved styles of coping, from the time of the CSA, to the time of the interviews. This change in coping styles could be attributed to changes in developmental stages [22], or that resilience is not a static construct [24]. This was evident in the manner in which the respondents described their childhood resilience, and how this had evolved over time, to the techniques they were currently using. This confirms that, as described by Walsh et al., [22] coping with CSA is a multifaceted process, one that is highly complex and dynamic.

The coping styles participants used were both extrinsic and intrinsic to the individual. The fact that resilience is not just an innate process, but one that can be fostered by factors external to the survivor, has also been posited by other researchers [25]. The positive coping styles survivors used, ranged from taking control of their lives, to seeking support from significant others. When asked how she has coped with the CSA, Participant Five said: 'I guess it was the support from mom... It got us closer'.

The positive internalized childhood resilience processes that the survivors utilized encompassed taking charge of their lives, which is similar to the Bogar and Hulse-Killacky [13] resilience process of taking control over their destinies. Survivors also reported that spirituality and prayer helped them cope with their experience. Coping through spiritual means has been identified as a way that survivors can deal with their experience [13, 20, 43, 44].

Further positive coping mechanisms identified included the use of critical self-talk and self-affirmations. These can be linked to the resilience processes of achieving closure, and to coping strategies outlined by Bogar and Hulse-Killacky [13]. Part of the process of self-forgiveness required the survivors to realize that they were not to blame, and to shift the blame to the perpetrator. As Participant Nine said:"I think I put all the blame on him and that helped 
a lot'. This formed part of the process that the survivor went through, moving from a place of self-blame to self-forgiveness. Self-blame is often one of the most challenging obstacles which a survivor has to overcome as part of their healing process, and often lasts into adulthood [45].

There were also certain negative coping styles which some survivors reported utilizing at the time of the CSA, such as denial and anger. They pointed out that they had used these initially, but had not used them over a long period of time. As Participant Two describes: 'I got all of the anger out, I'd dance and sing, and um, like all the anger that I felt I wrote down, and I turned it into stories'. Walsh et al., [22] and Whiffen and McIntosh [46] argue that these negative coping styles are often used in the short-term, during the initial processing of the event; however, this form of coping will frequently lead to negative outcomes in the long run [22], such as higher levels of emotional distress. This attests to the dynamic nature of the resilience process which survivors go through.

In childhood, the external methods of coping which the survivors reported to help them cope with the CSA, was reaching out to others around them. Survivors reported reaching out to various people such as parents, friends and partners. As Participant two stated: 'I think it helped me cope, um, just by talking'. Having the support of other people during this time has been found to be an adaptive coping style, one that decreases the survivors' psychological distress [20, 44, 47]. This is essential because a survivor needs a support-base which is secure and caring, in order to aid the healing process. The individual needs others, whom she or he can trust, and in whom she or he feels able to confide about the experiences. This shows the reciprocal relationship between these extrinsic and intrinsic factors. The importance of attachment is discussed in the full research study on which this research is based [48].

Rutter [24] posits that receiving support as a form of coping has been found to have a significant impact on the resilience process [24], and could bring about positive and adaptive outcomes [22]. Having the support of others within a cohesive family environment (for example, one characterized by trust and open communication), has been linked to increased self-efficacy, which brings about a sense of environmental mastery, and as such, an ability to master life's challenges [47].

In relation to their adult resilience processes, participants still utilized both intrinsic and extrinsic forms of coping. Their positive intrinsic coping styles appeared to have become more developmentally mature, and were more self-reflective in nature. From the themes it became apparent that the participants were able to regain homeostasis through self-reflection, changing their mind-sets and critical self-talk. Thus, cognitive restructuring, and finding new ways of understanding and thinking about the event, were ways that survivors found to cope with their experiences. Such styles of coping have been identified as adaptive ways of dealing with a CSA [20]. As described by Walker-Williams et al., [20] this was a process of learning to reshape the way they thought about what had happened to them. The use of critical self-talk was also a way that survivors challenged themselves and restructured their cognition surrounding the event. Participant Six stated the following: 'I just convinced myself that it wasn't my fault. Because I know that if I blamed myself then I would have lost it. So I think from a young age I just told myself ... this is going to stop one day, it's fine, it's going to be ok'.

As Walsh et al., [22] explain, in order for CSA survivors to learn to cope with their experience, they need to take on these types of adaptive coping styles, as it is through this process, that they manage to integrate their CSA into their current cognitive frame of reference [22]. The amelioration of the negative long-term consequences of CSA, through the implementation of cognitive restructuring and processing, has been suggested, since some of the earliest research into resilience was conducted in the field of CSA [28]. Rutter [24] suggests that the cognitive processing of experiences, allows the survivor to attach meaning to their experience, finally process it, and this in turn facilitates the process of resilience.

Most of the coping resources that the survivors utilized showed the emergence of a strong sense of self-esteem and positive adjustment. The importance of having an internal locus of control, appropriate cognitive coping styles, externalizing the blame, and religion, were also highlighted as important recovery processes $[42,49]$.

Researchers have stated that it is erroneous to even consider that a CSA survivor should have to attempt to cope with their experience on their own [18]. Instead, the dynamic interplay that exists between the child and the environment, affects the child's ability to cope. In actual fact, it acts as a mediator between the child and the adverse experience. The participants identified external support as a necessary tool that continued to help them cope. This again highlights the importance of viewing this as a process which continues over time.

Therefore, the coping skills a CSA survivor utilizes, act as a mediator for the outcomes they experience, with different styles of coping bringing about different outcomes. In this research study, a number of themes were identified. Some were overarching themes, and others were unique. Even within the main overarching themes, the participants' descriptions were unique to their experience. This highlights the true complexity of the resilience process, and how it is highly subjective in nature.

\section{Conclusions}

The findings of this study support the theory that resilience acts as a possible mediating factor to the 
psychosocial sequelae a CSA survivor might experience. Therefore, reconceptualization of the term 'resilience' is vitally important, as it has significant ramifications for individuals who have been exposed to traumatic events, specifically in this case, to childhood sexual abuse. Viewing resilience as an outcome, a specific goal that a survivor needs to achieve, might in fact lead to more deleterious effects. This is because a true and continued state of resilience may not even exist, leaving individuals feeling inadequate, and unable to achieve this goal. However, seeing it as a process, allows for the survivor and individuals who work with CSA survivors (such as health care practitioners), to adapt the manner in which they understand resilience.

When exploring the concept of resilience, and its role as a possible mediating factor regarding the outcomes a survivor might experience, one must continually keep in mind the three core factors, namely, that resilience should be considered a subjective, context specific and process-centered approach.

The first factor to consider is that resilience is a process $[4,18]$ however, with this understanding; it becomes difficult to quantitatively measure the concept retrospectively, as it is not static. This is why a mixed methods approach was used, as it shed light on the complex nature of resilience. Through the findings elicited from Phase 1, it became apparent that there were no statistically significant differences between the resilience scores of the incident and the no-incident group. Through further analysis of the findings from Phase 2, it was discovered that survivors had shifted in their styles of coping, from the time of the CSA, to the present. This shed further light on the findings elicited in Phase 1 and led to Phase 3, where these findings were integrated, resulting in the conclusion which confirms the hypothesis that resilience is a process that seems to change over time. It seems to change as the individual progresses through different developmental stages [22]. In the short-term it seemed that some survivors tended to use defensive coping mechanisms to deal with the aftermath of the abuse. This allowed them to initially 'bounce back' from the experience. The survivors soon found that these mechanisms could not be maintained for the long-term, and then turned to other more positive and adaptive ways of coping.

As the survivors aged, their positive coping styles matured with them. This leads to the second concept that resilience is largely a subjective construct. This links to the highly cognitive and individualized nature of this form of coping. The way in which a person conceptualizes their experience contributes to their resilience [50]. The process of cognitive restructuring [20], the self-reflection and meaning-making [27; 43], which play a part in the process of recovery, are all intrinsic to the individual.

The final concept is that resilience is partly event specific. When exposed to a specific trauma one learns to cope and deal with that trauma, and this process builds resilience. Two views exist on the impact that this has on an individual's future resilience, and, in fact, both have a role to play. One view is that once the individual has discovered his or her ability to be resilient in the face of trauma, they learn that future stressors can be overcome. As a result, they are less overwhelmed than they might have been, had the person not developed this resilience [21, 51]. The other view is that resilience is not a fixed structure, meaning that success in overcoming one adversity, does not mean that the individual is immune from future traumatic experiences $[18,52]$, and that resilience does not necessarily translate across all life experiences [3].

These three concepts can then be used to explain the results of the Resilience Scale (RS) extrapolated during Phase 1. Resilience is not static; it is a process. It is a mechanism that individuals employ to deal with daily stressors which are experienced. Every now and again these stressors could possibly amount to a crisis or trauma. It appears that the coping resources survivors marshal to deal with these events are often specific to the event at hand. However, their ability to cognitively reframe their thoughts, their ability to problem solve, and their ability to make meaning out of the challenges they experience, does appear to place them at a greater advantage to deal with any future crisis they might experience. It was found that the CSA survivors were not any worse off psychologically than their non-sexually abused counterparts, and that their resilience had aided them in dealing with their previous trauma. It facilitated their growth to continue with life to the point which they could enter university, and function at similar levels of resilience as the other students who were assessed. Their use of process-centered resilience buffered the long-term effects of their CSA, to an extent that they could function at the level of what would be considered 'normal' resilience levels.

Therefore, process-centered resilience should be seen as a dynamic process mediating the impact which an adverse life event has on an individual, allowing the individual to achieve an adaptive level of coping. This process is not fixed, and depends on the adversity, the context, the developmental stage of the individual, and the support that the individual has at the time of the experience. It highlights the importance of going through a process of resilience, of realizing that certain steps can be followed to assist with their coping. This could offer valuable information for health-care practitioners (psychologists, social workers or nurses) in how they approach and help survivors cope with their experience. The questions highlighted earlier have been addressed through the proposed reconceptualization of resilience as a process that is event specific.

\section{Limitations and Implications for Future Research}

One possible limitation could be that the data was related to the participants' retrospective accounts of their CSA. 
However, research has shown that when the information being recollected is from an event that had a significant impact on a participant's life, then he/she is more likely to have a clearer memory of the incident [53].

Another concern is that a retrospective account might not represent an accurate picture of the current chronology of these types of events [53]. However, it is the opinion of the researcher, that after reviewing extensive CSA literature conducted over the past 20 years, and reports by other reviewers [for example, 54], that the nature and characteristics of this phenomenon remain generally consistent. Future research into the development of a clear operational definition of resilience is needed, as this will have a great impact on the intervention methods which are utilized to treat childhood sexual abuse survivors. It is recommended that this be done in a variety of fields, in order to develop context specific models that can be used in treatment paradigms.

\section{REFERENCES}

[1] M. Rutter. Psychosocial resilience and protective mechanisms. American Journal of Orthopsychiatry, 57(3), 316-331, 1987.

[2] G. A. Bonanno, M. Westphal, A. D Mancini. Resilience to loss and potential trauma. Annual Review of Clinical Psychology, 7(1), 511-535, 2011.

[3] L. McCubbin. Challenges to the definition of resilience. Paper presented at the Annual Meeting of the American Psychological Association $\left(109^{\text {th }}\right)$, San Francisco, CA, 2001 Online available from http://files.eric.ed.gov/fulltext/ED458498.pdf.

[4] H. Herrman, D. E. Stewart, N. Diaz-Granados, E. L. Berger, B. Jackson, T. Yuen. What is resilience? Canadian Journal of Psychiatry, 56, 258-265, 2011.

[5] M. Rutter. Resilience concepts and findings: implications for family therapy. The association for Family Therapy, 21, $119-144,1999$.

[6] S. S. Luthar, D. Cicchetti, B. Becker. The construct of resilience: A critical evaluation and guidelines for future work. Child Development, 71, 543-562, 2000.

[7] L. Iaccino. Child sexual abuse: Top 5 countries with the highest rates. International Business Times. Online available from http://www.ibtimes.co.uk/child-sexual-abuse-top-5-countri es-highest-rates-1436162, 2014, February, 12.

[8] L. Artz, P. Burton, C. Ward, L. Leoschut, J. Phyfer, S. Lloyd, R. Kassanjee, C. Mottee. Optimus Study South Africa: Technical Report Sexual victimisation of children in South Africa Final report of the Optimus Foundation Study: South Africa. Augustinerhof 1, 8098 Zurich, Switzerland: UBS Optimus Foundation, 2016.

[9] Centers for Disease Control and Prevention. The adverse childhood experiences (ACE) Study. Atlanta, Georgia: National Center for Injury Prevention and Control, Division of Violence Prevention, 2014.

[10] C. F. Whitelock, M. E. Lamb, P. J. Rentfrow. Overcoming trauma: Psychological and demographic characteristics of child sexual abuse survivors in adulthood. Clinical Psychological Science, 1(4), 351 - 362, 2013. doi: $10.1177 / 216770261348013$

[11] H. Larkin, B. A Beckos, J. Shields. Mobilizing resilience and recovery in response to adverse childhood experiences (ACE): A restorative integral support (RIS) case study. Journal of Prevention \& Intervention in the Community. 40. 335-46, 2012. doi: 10.1080/10852352.2012.707466

[12] S. M. Southwick, G. A. Bonanno, A. S. Masten, C. Panter-Brick, R. Yehuda. Resilience definitions, theory, and challenges: interdisciplinary perspectives. European Journal of Psychotraumatology, 5, 1 - 14, 2014.

[13] C. Bogar, D. Hulse-Killacky. Resiliency determinants and resiliency processes among female adult survivors of childhood sexual abuse. Journal of Counseling \& Development, 84, 318 - 328, 2006.

[14] I. Daigneault, M. Cyr, M. Tourigny. Exploration of recovery trajectories in sexually abused adolescents. Journal of Aggression Maltreatment and Trauma,14(1/2),165-84, 2007.

[15] T. O. Afifi, H. L. Macmillan. Resilience following child maltreatment: a review of protective factors. Canadian Journal of Psychiatry, 56(5), 266 - 272, 2011.

[16] K. M. Anderson, C. Hiersteiner. Recovering from childhood sexual abuse: Is a "storybook ending" possible. The American Journal of Family Therapy, 36, 413 - 424, 2008. doi:10.1080/01926180701804592

[17] V. E. Frankl. Man's search for meaning. New York: Pocket Books, 1985.

[18] M. Neenan. Developing resilience: A cognitive-behavioural approach. New York: Routledge, 2009.

[19] S. Valenica, J. Shakespeare-Finch, P. Obst. Exploring the process of meaning making in healing and growth after childhood sexual assault: A case study approach. Counselling Psychology Quarterly, 26(1), 39 - 54, 2013. doi: 10.1080/09515070.2012.728074

[20] H. J. Walker-Williams, C. van Eeden, K. van der Merwe. Coping behaviour, posttraumatic growth and psychological well-being in women with childhood sexual abuse. Journal of Psychology in Africa, 23(2), 259 - 268, 2013

[21] G. M. Wagnild. The resilience scale users guide. Montana, USA: The Resilience Centre, 2010.

[22] K. Walsh, M. A. Fortier, D. DiLillo. Adult coping with childhood sexual abuse: A theoretical and empirical review. Aggression and Violent Behavior, 15(1), 1 - 13, 2010. doi:10.1016/j.avb.2009.06.009

[23] G. Wu, A. Feder, H. Cohen, J. J. Kim, S. Calderon, D. S. Charney, A. A. Mathé. Understanding resilience. Frontiers in Behavioral Neuroscience, 7(10), 2 - 15, 2013.

[24] M. Rutter. Resilience concepts and findings: implications for family therapy. The Association for Family Therapy, 21, $119-144,1999$.

[25] M. Domhardt, A. Münzer, J. M. Fegert, L. Goldbeck. Resilience in survivors of child sexual abuse: A systematic 
review of the literature. Trauma Violence \& Abuse, 16(4) 476-493, 2015. doi: $10.1177 / 1524838014557288$

[26] L. C. Theron, A. M. C. Theron. A critical review of studies of South African youth resilience, 1990-2008. South African Journal of Science, 106(7/8), 2010. Online available from http://www.sajs.co.za

[27] T. N Phasha. Educational Resilience Among African Survivors of Child Sexual Abuse in South Africa. Journal of Black Studies, 40 (6), 1234-1253, 2010. doi:10.1177/0021934708327693

[28] M. J. Himelein, L. D. Edwards, K. W. Hisel, J. V McElrath. Resilience in child sexual abuse survivors: Healing power of illusions. Paper presented at the Annual Meeting of the Southeastern Psychological Association, New Orleans, LA, 1994. Online available from http://files.eric.ed.gov/fulltext/ED37002 8.pdf

[29] C. Teddlie, A. Tashakkori. Major issues and controversies in the use of mixed methods in social and behavioural sciences, pp 3 - 50. In A. Tashakkori \& C. Teddlie. (Eds.). Handbook of mixed methods in social and behavioural research. California: Sage Publications, 2003.

[30] R. S. Miller, J. A. Johnson, J. K. Johnson. Assessing the prevalence of unwanted childhood sexual experiences. Journal of Psychology and Human Sexuality, 4(3), 43-52, 1991.

[31] M. Murthi, H. L. Servaty-Seib, A. N. Elliott. Childhood sexual abuse and multiple dimensions of self-concept. Journal of interpersonal Violence, 21, 982-999, 2006. doi: $10.1177 / 0886260506290288$

[32] B. Rind, P. Tromovitch, R. Bauserman. A meta-analytic examination of assumed properties of child sexual abuse using college samples. American Psychological Association, 124(1), 22-53, 1998.

[33] D. N. Roche, M. G. Runtz, M. A Hunter. Adult attachment: a mediator between child sexual abuse and later psychological adjustments. Journal of Interpersonal Violence, 14, 184-207, 1999.

[34] R. S. Miller, J. A. Johnson. Early sexual experiences checklist. In C.M. Davis, W.L. Yarber, R. Bauserman, G. Schreer, \& S.L. Davis (Eds.), Handbook of sexuality-related measures (pp. 23-25). London: Sage Publications, 1998.

[35] T. E. M. Defferary, L. J. Nicholas. Assessing students' unwanted early sexual experiences. Africa Journal for Physical, Health Education, Recreation and Dance, 18(2), 350-360, 2012.

[36] G. M. Wagnild, H. M. Young. Development and psychometric evaluation of the resilience scale. Journal of Nursing Measurement, 1(2), 165-178, 1993.

[37] A. K. Hutchinson, A. D. Stuart, H. G. Pretorius. Biological contributions to well-being: The relationship amongst temperament, character strengths and resilience. South African Journal of Industrial Psychology, 36(2), 844-854, 2010.

[38] J. W. Creswell. Research design: Qualitative, quantitative, and mixed methods approach. (4th ed). Los Angeles: Sage Publications, 2014.
[39] Y. S. Lincoln, E. G. Guba. Naturalistic Inquiry. California USA: Sage Publications, 1985.

[40] Health Professions Act, South African Statutes, s12, 2006.

[41] A. Allen. Law and ethics in psychology: An international perspective. Somerset West: Inter-Ed, 2015.

[42] H. Forester-Miller. T. Davis. A practitioner's guide to ethical decision making. American Counselling Association, 1996. Online available from http://www.alabamacounseling.org/pdf/acaguide.pdf.

[43] B. J. Arias, C. V. Johnson. Voices of healing and recovery from childhood sexual abuse. Journal of Child Sexual Abuse, 22(7), 822-41, 2013. doi:10.1080/10538712.2013.8 30669

[44] M. Sumari, C. Lee Ping. Healing experience of a woman survivor of childhood sexual abuse. The International Journal of Research and Review, 5(2), 24 - 29, 2010.

[45] H. H. Filipas, S. E. Ullman. Child sexual abuse, coping responses, self-blame, posttraumatic stress disorder, and adult sexual revictimization. Journal of Interpersonal Violence, 21, 652-672, 2006.

[46] V. E. Whiffen, H. B. MacIntosh. Mediators of the link between childhood sexual abuse and emotional distress: A critical review. Trauma, Violence \& Abuse, 6, 24-39, 2005.

[47] F. H. McClure, D. V. Chavez, M. D. Agars, M. J. Peacock, A. Matosian. Resilience in sexually abused women: Risk and protective factors. Journal of Family Violence, 23, 81-88, 2008. doi:10.1007/s10896-007-9129-4

[48] T. E. M. Defferary, J. G. Howcroft, L. A. Stroud. Resilience and Attachment as Mediators Impacting upon the Psychosocial Sequelae of Unwanted Early Sexual Experiences. 15th European Congress of Psychology Amsterdam, Netherlands, July, 2017.

[49] L. Valentine, L. L. Feinauer. Resilience factors associated with female survivors of childhood sexual abuse. American Journal of Family Therapy, 22(3), 216 - 224, 1993.

[50] M. Rutter. Annual research review: Resilience - clinical implications. Journal of Child Psychology and Psychiatry, 54(4), 474-487, 2013.

[51] L. Ming-Hui. Relationships among stress coping, secure attachment, and the trait of resilience among Taiwanese college students. College Student Journal, 42(2), 312-326, 2008 .

[52] E. Norman. The strengths perspective and resiliency enhancement: A nature partnership. In E. Norman (Ed.), Resiliency enhancement: Putting the strengths perspective into social work practice, (pp. 1-16). New York, NY: Columbia University Press, 2000.

[53] E. K. Martin, P. H. Silverstone. How much child sexual abuse is "below the surface," and can we help adults identify it early? Frontiers in Psychiatry, 4, 1-10, 2013. doi: 10.3389/fpsyt.2013.00058

[54] N. Pereda, G. Guilera, M. Forns, J. Gómez-Benito. The international epidemiology of child sexual abuse: A continuation of Finkelhor (2004). Child Abuse \& Neglect, $33,331-342,2009$ 